\title{
THE COOLING OF THE CYLINDERS OF
}

\section{HIGH-SPEED INTERNAL-COMBUSTION ENGINES,}

AND ITS EFFECT UPON THE POWER DEVELOPED.

By Professon II. S. HWLF-SIIAW, LL.D., F.R.S., Member, OF LiVERPOOL.

In response to an invitation to bring some subject which might be of interest before the present Engineering Congress, it occurred to the author that there was one which, though at the present time exciting attention chiefly amongst automobilists, has (in the rapid development in the powerfulness of small high-speed oil and spirit engines) a direct interest for engineers in general. This subject is the over-heating of the cylinders, and its prevention.

In comparatively large, slow running, stationary oil or gasengines it is easy enough to have a water-jacket with one or two fairly large tanks of cooling water; but, upon a motor car, whero weight is a prime consideration, the matter of cooling is one which causes great trouble, and the provision for which has involved arrangements of great ingenuity. In quite small motor vehicles, such as motor bicyles and tricycles, and even the small voiturette, -that is, with engines up to 3 H.P. - the movement of the vehicle through the air, or the provision of a revolving fan, is taken advantage of for the purpose of cooling the cylinders by air, the cylinders being provided with a small number of webs for this purpose. In a French engine which the author tested a short time ago, four cylinders, nominally of about 3 H.P., revolved at a 
high speed in a horizontal plane round a fixed crank-shaft, and after some hours' run in a heated workshop, it was possible to bear the hand upon the outside of the cooling ribs of the cylinders, although upon standing the heat was rapidly conducted outwards. Certain constructional dofects in the engine prevent the full power being obtained; and it cannot be known until these are remedied, whether the air-cooling is really effective in this type of engine.

With small engines air-cooling is fairly effective in quite cold weather, but in hot and dry weather (which is, of course, chiefly the time when motor vehicles are in requisition) even small engines of little more than 1 H.P., rapidly become heated with a corresponding falling off in propelling power, ultimately stopping altogether. No doubt, by careful management in the way of continual regulation in the admission of gas into the carburetter, and great watchfulness in taking advantage of every descent of a bill to cool the cylinder, and, further, by being content with a moderate speed of the engines, an air-cooled cylinder of $2 \frac{3}{4}$ to 3 H.P. can be kept cool even upon a fairly hot day. The author has however recently had some experience with two tricycles, one having a $2 \frac{3}{4}$-H.P. engine, aircooled, and another with a water-cooled head of the same power, the latter being the most recent type of $\mathrm{De}$ Dion motor, in which a small tank of water carried behind the saddle, and a small radiator, through which the water circulates by gravitation, are employed. He has no hesitation in saying that the power developed in the latter case has been very much greater than in tho former, while there is no comparison whatever in the distance which can be covered on a hot day by the two machines, to say nothing of the satisfaction of being able to ride mile after mile at a high speed, without the slightest anxiety about climbing any hills which may be met, even in such a ride as from Carlisle to the east of Fife.

The author has had a similar experience with regard to his twocylinder "New Orleaus" voiturette. This voiturette, in spite of many defects such as are probably to be found in most motor cars, is a fast little car ; and the air-cooled cylinders, which have a fan revolving between them, can, in quito cold weather, or even with an abnormal amount of care in hot weather, be made to run very well. 
In hot weather, however, he has experienced so much annoyance with the heating of the cylinders upon a long run, that he first of all adopted the plan of allowing water to drop upon the air-cooled cylinder-head from a reservoir when he found the cylinder was getting hot, but afterwards decided to replace the air-cooled heads with water-cooled heads. Since doing this he has never had any trouble whatever with the heating of tho cylinders, or experienced any diminution in power from this cause. On one of the hottest days of the year this voiturette went about a hundred miles, and returned a few days later without his experiencing any trouble, at any rate, from this cause. A number of communications have reached the author from people who have evidently experienced trouble with these cars, asking for details of the water-cooling arrangement; and it may, thercfore, be interesting to describe briefly the details which are illustrated in a diagrammatic way in Fig. 1 (page 788). The hollow water-cooled heads $\Lambda A$, together with valve chambers $B B$, which are in one solid picce, replace the ordinary ribbed head and valve chamber. The hot water rises directly from the centre of the top of the cylinder-head by the pipe $\mathrm{C}$, discharging at the top of the copper cylinder DD, while the circulation is maintained by the descending water passing out at the bottom of the copper reservoir by the pipe $\mathrm{E}$ through a copper coil which is shown in plan at $\mathrm{F}$. The circulation through one cylinder is entirely separate from that in the other, and complete in itself, both having, of course, a common reservoir in the copper cylinder $\mathrm{DD}$, the level of water in which is shown by means of a water-gauge $\mathrm{H}$.

It is interesting to notice when the engine starts how a warm layer can be felt by putting the hand on the top of the copper cylinder DD, while all the rest of the system remains quite cold, and how, as the engine continues to work, the zone of heat travels downwards, showing how the hot water rises immediately and remains on the top, and indicating the perfect nature of the circulation. It was on a large car where the author first saw a similar system of circulation employed by Mr. Esteourt with most satisfactory results. In view of all the trouble with cars in which pumps are used, as they generally are, it seems a pity that circulation by means of gravity cannot always be cmployed. 
Figr. 1.

Diagrammatic Sletch of Water-Cooling Arrangement in Voiturette.
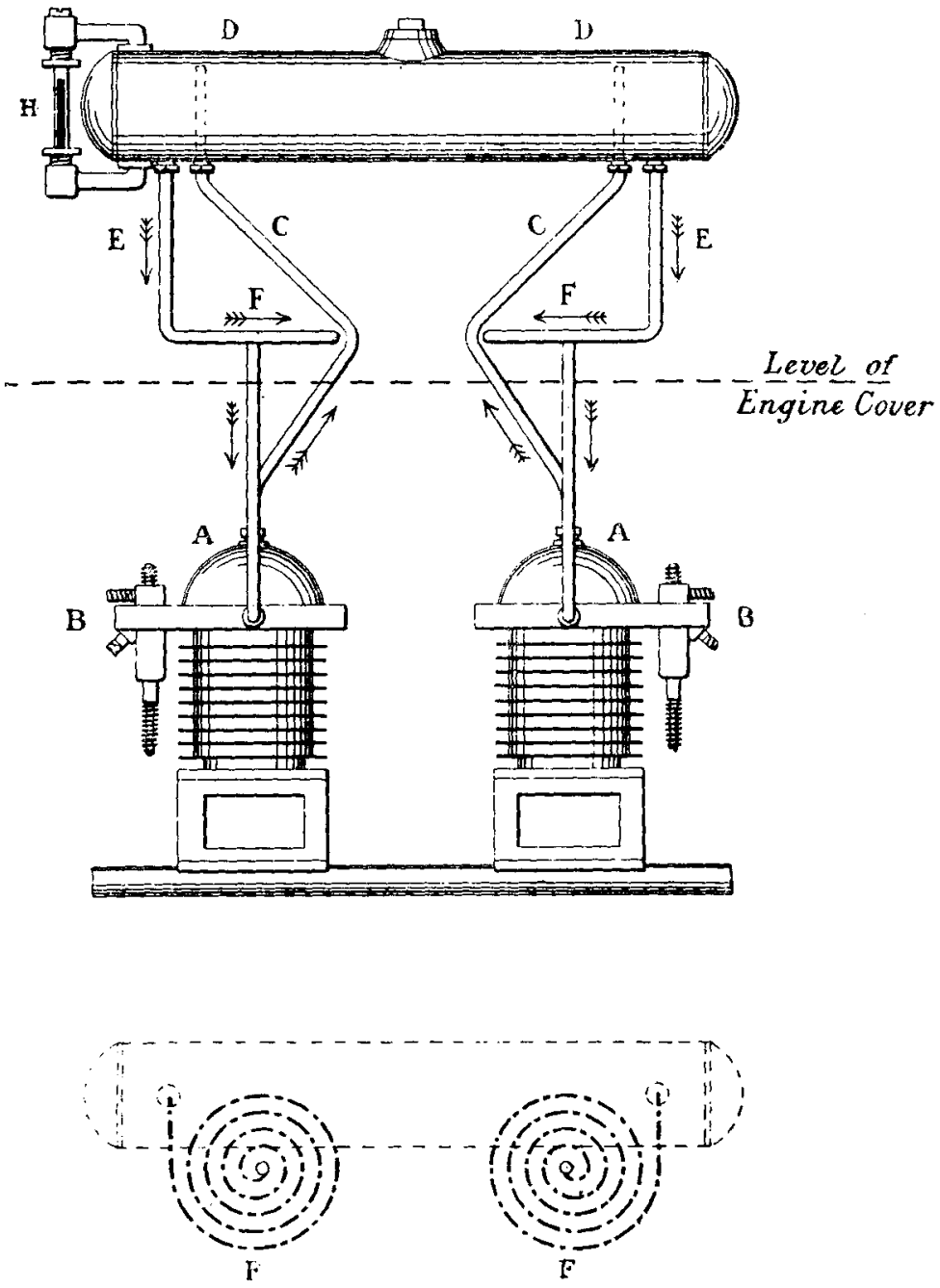
Both with the tricycle mentioned and with the above voiturette the water on a hot day during a long run is for considerable periods at a time on the boil, without the power in any way appearing to appreciably diminish; whereas, on the other hand, he has been on larger cars where, owing to the defective working of the pump, the water was not circulating properly, and a considerable amount of steam was being formed. In the latter cases the power fell off in a very serions manner, although the engine never actually stopped, as has been seen with air-cooled motors. It is clear, on a little consideration, that the rate at which water is boiling off, and not the actual fact that water is in contact with the cylinder walls, must be largely a measure of internal heat of the cylinder. On the other hand, amongst those who are accustomed to drive motor cars, there is generally a feeling that the engines work best at a certain temperature somewhere between that at which the water boils off, and the cold state in which the engine actually starts. The anthor has not been able to find that there exist any actual data upon this subject, and it seemed to be a sufficiently important matter to be worth making some experiments upon. He has, therefore, with the assistance of Mr. Gill, B.Sc., engineering student of the University Collego of Liverpool, experimented upon the 6-H.P. engine represented in Fig. 2 (page 790). This engine, which has magnetic electric ignition, was fitted with two thermometers, A measuring the water at entrance and $B$ that at exit. $C$ is a tank which was used when the water was allowed to remain at boiling point, but otherwise the two pipes were connected with the mains, and the water at exit kept at the temperature required by allowing a sufficiontly rapid flow of water through the eylinder-jacket. 1 is the flywheel upon which a dynamometer brake acts, so that the power can be accurately tested. A series of five trials were made, four with the water at different temperatures, and the fifth with glycerine circulating in the cylinder-jacket and tank instead of water, in order to obtain a higher boiling point and a higher temperature of the cooling liquid.

The general result of these trials is given in the following Table and plotted in Fig. 3 (page 792), in which the ordinates 

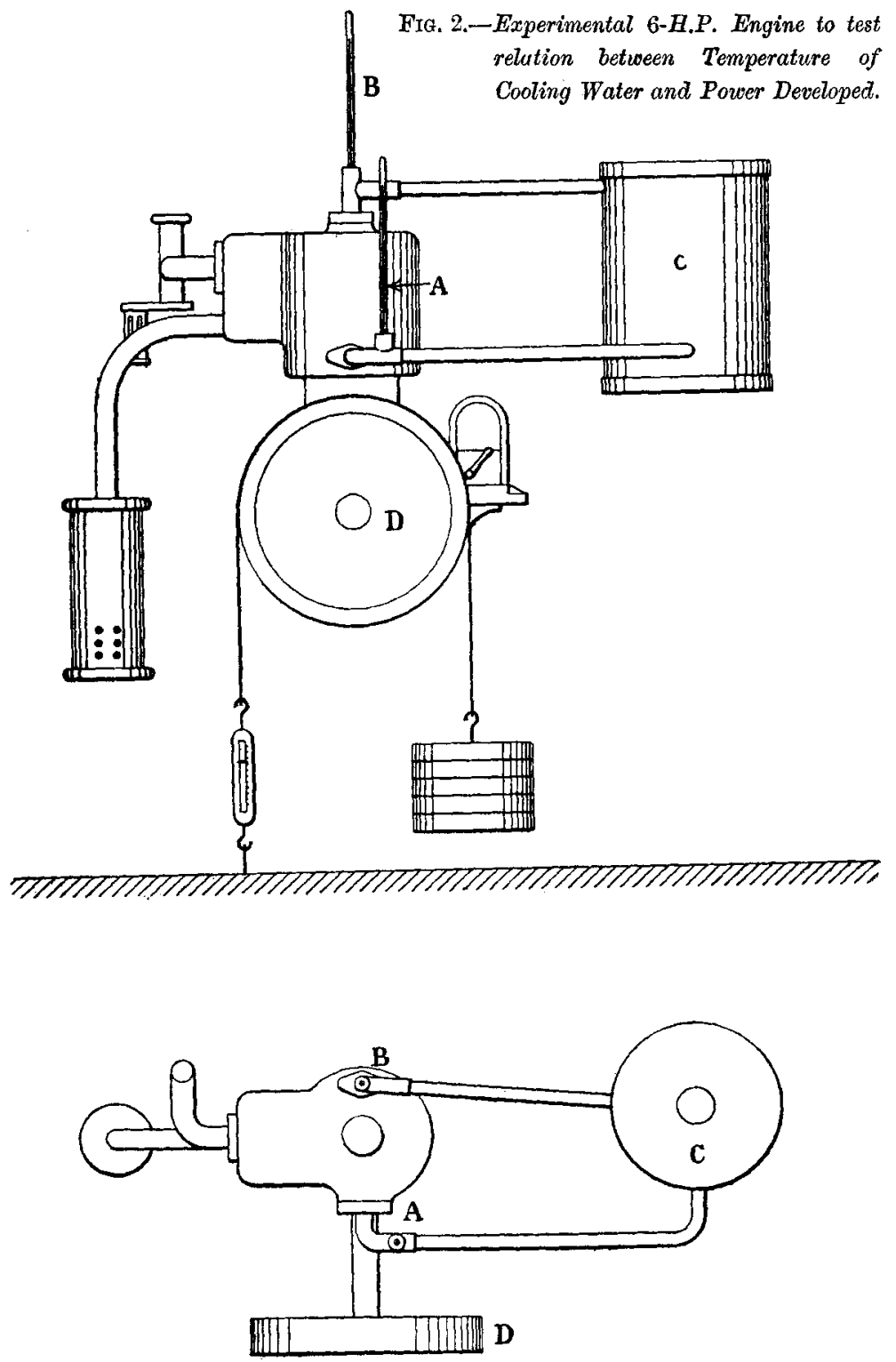
represent brake horse-power (which it will be seen under the best circumstances never exceeded about $4 \frac{3}{4}$ ), whereas the abscissm represent the temperature of the water at exit. The two series of boiling-off experiments have been kept separate from the other three, but the plotted results indicate the same general result:-

Summary of Tests.

\begin{tabular}{|c|c|c|c|c|}
\hline \multirow{2}{*}{ Trial No. } & \multicolumn{2}{|c|}{ 'Temperature } & B.H.P. & Revs. \\
\hline & at Entry. & at Exit. & & \\
\hline 1 & F.' & F.० & & \\
2 & $66 \cdot 2$ & $77 \cdot 0$ & $4 \cdot 775$ & 1086 \\
3 & 64.4 & 131.0 & $4 \cdot 47$ & $108 t$ \\
4 & $64 \cdot 4$ & $212 \cdot 0$ & $3 \cdot 97$ & 903 \\
\hline 5 & $212 \cdot 0$ & $212 \cdot 0$ & $4 \cdot 07$ & 925 \\
\hline
\end{tabular}

Iu experiments 1,2 , and 3 , the water was running through.

In experiment 3 only a small quantity was allowed to flow, as it was completely evaporated.

Nos. 4 and 5 were boiling-off experiments.

In No. 5 Glycerine was used.

The general nature of these experiments is immediately obvious, and indicates a falling off in brake horse-power as the temperature rises, the brake horse-power between the two extremes of temperature having fallen from $4 \cdot 775$ to $3 \cdot 94$, a diminution of about 17 per cent.

Each series of experiments represents roughly speaking about ten observations, which were conducted as carefully as possible; but, at the same time, the difficulties of maintaining uniformly the temperature and speed of the engine were sufficiently great to make it undesirable to attempt to produce any mathematical statement from these results; further and more elaborate experiments will be required of temperature taken in conjunction with the actual 
FIG. 3.-Showing relation between Temperature of Cooling Water and B.H.P.

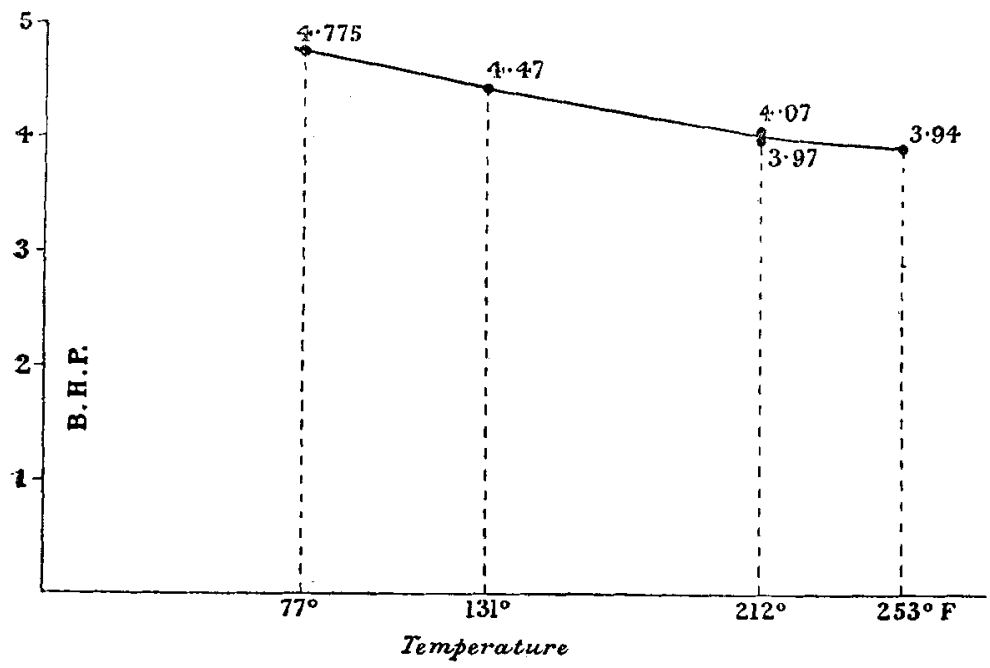

quantity of water used, before any definite conclusion can be arrived at on this subject. It is interesting to note that Mr. Dugald Clerk, in reply to a letter from the author asking for information, appears to have obtained with a slow-running gas-engine slightly greater efficiency at the higher temperatures; but, of course, the foregoing experiments only deal with actual power, and not with efficiency.

The author has not attempted to discuss the actual cause or causes of the falling off in power as the temperature of the cylinder rises. Whether this is due to Iubrication diffeculties or thinning of the cylinder lubricant to a point which allows the piston rings to leak, or whether due to heating of incoming charge and consequent weakening of the mixture, would afford matter for an interesting discussion.

The adrances in the construction of these high-speed, internalcombustion engines, and the rapidly increasing power which is being evolved from them warrants their careful study. Thus in the recent Paris-Berlin race there were several engines upon light 
motor vehicles capable of developing more than 50 H.P., with in one case at least a weight of not more than $10 \mathrm{lbs}$. per horse-power. When it is remembered that this is not merely the equivalent of the steam-engine, but of the engine and boiler, it will no doubt be admitted that any of the points, such as the cooling of the cylinders, which is an essential feature of the problem, is worthy of the attention of this Congress.

The Paper is illustrated by 3 Figs. in the letterpress.

\section{Discussion.}

The Chairman said that Professor Hele-Shaw had brought before them a question which was of very great importance at the present time. Before asking them to discuss his Paper, he would call upon them to pass a hearty vote of thanks to the author for the trouble he had taken in coming there that day to read his communication.

Mr. Bryan Donkin, Vice-Chairman, asked whether Professor Hele-Shaw had taken the quantity as well as the rise in temperature of the cooling-jacket water, so as to get the total number of thermal units. Some further experiments on this point would be desirablo.

Herr R. Dieser said that the great number of very exact experiments, which he had made, confirmed the main fact told by Professor Hele-Shaw, namely, that the power of internal-combustion motors decreased very rapidly with the increase of the temperature of walls.

Mr. Blackwood MurRay thought it would be interesting if Professor Hele-Shaw would inform them by what amount the torque would diminish with the rise of temperature. His firm's experience 
(Nr. Blactis wood Murray.)

had been that, with engines running at the moderate speed of 500 to 700 revolutions, there was a slow increase from $60^{\circ} \mathrm{F}$. up to about $100^{\circ}$, and then on to the boiling point the torque was almost constant. These engines were fitted with governors. Again, the amount of water-jacketing on the cylinder had a very important bearing on the subject. With engines partially water-cooled, the body of the cylinder was usually at a much higher temperature than $212^{\circ}$, and the lubrication of the cylinder in such cases was very difficult; the torque was consequently much decreased. He would be obliged if Professor Hele-Shaw would give the torque at the various temperatures.

Professor Hele-Shaw asked what was the horse-power of the engine referred to.

Mr. Muraay said the horse-power was from 7 to 8 horse-power, the two cylinders being 4 inches diameter and 7 inches stroke.

Mr. Bryan Donkin enquired what was the percentage of surface jacketed of the total internal area.

Mr. Muraty replied that the whole travel of the piston was water-jacketed, and the whole of the valve chamber also.

Mr. Dugand Cherr had many years ago made some experiments on the effect of temperature upon the power produced by gas-engines. The first experiment was with one of his own engines, the old Clerk type in which the cylinder was 9 inches diameter and the stroke 24 inches. The whole of the cylinder was water-jacketed. Going from ordinary temperature, $60^{\circ} \mathrm{F}$. up to the boiling point, he found a steady increase of cfficiency with a slight decrease of power, with an increased economy.

In a letter he had written to Professor Hele-Shaw he thought the Professor was enquiring as to heat efficiency, not power. There was a drop in power, but an improvement in economy up to a certain point. The reason of that was fairly evident. In a gas- 
engine or oil-engine the power depended upon the weight of the charge within the cylinders, when the stroke was complete. In the case of a charge having double the absolute temperature of another charge, there was only half the weight of material present; the result was an engine which gave less power, but a greater economy might be obtained. In the small motors which were used in the motor trials that week, it was very difficult to reason in exactly the same way as with a large gas-engine cylinder using slow speeds. In Fig. 1 (page 788) the cylinder was cooled by radiated ribs and air contact, and the caps and cylinder covers were alone water-cooled. In that engine the temperature of the cylinder and the temperature of the piston, which determined the temperature of the charge, would be very different from the temperature of the water leaving the cylinder head. In the same way, in Fig. 2 (page 790), although a water-jacket included practically the whole stroke of the piston, yet the piston itself projected into a part of the cylinder, which was not water-jacketed, and the lower part got very hot. The efficiency of an engine with increasing water temperature improved up to a certain point, and then fell off again. Experiments with the small aircooled motors showed a lower efficiency, because the temperatures of the cylinders were somewhat in the neighbourhood of $400^{\circ} \mathrm{C}$, which was over-doing it. When the temperatures were so high as that, the efficiency dropped as well as the power: the problem was rather complex, and one had to consider carefully whether power or efficiency was being dealt with; the power invariably dropped. He thought there was no doubt that engineers accustomed to gas-engines had always known and felt that up to a certain point the heating efficiency increased, and his own experiments showed that it increased up to about boiling point.

The Chamman, before requesting Professor Hele-Shaw to reply, would like to ask two questions with regard to Fig. 1 (page 788). He observed there that the pipes $C$ were carried very nearly to the top of cylinder DD. Were they really carried so near as there shown, because, if there was any loss of water, that would prevent any circulation taking place. He did not know whether any provision 
(The Chairman.)

had been made for that contingency. The other point was whether the cylinder DD was completely closed, or whether there was an escape valve for any vapour formed.

Professor Helk-Shaw in reply, said, in answer to the question of Mr. Donkin (page 793), he did not measure the quantity of water passing, and did not profess to have dealt with the subject of efficiency as measured by the heat carried off by the water. The temperature of the outcoming water was just a rough indication of the heat of the cylinders. He was very pleased to see that the general results of his experiments were accepted by the various gentlemen who had joined in the discussion, as agreeing with their own experience. He was glad they had had amongst them Herr Diesel, who was so well known and had done so much in the direction of internal-combustion engines, and apparently his experience coincided with what he himself had found on a small scale.

Mr. Blackwood Murray had asked about the torque. The torque increased slightly up to about $135^{\circ} \mathrm{F}$, and then fell off. In regard to the remarks of Mr. Dugald Clerk, it was only a question of power that he had there considered, and not a question of efficiency. Driving motor cars was a very expensive matter, and a few ounces more or less of petrol was nothing, as petrol cost about $\frac{1}{2} d$. a mile and tyres cost probably about $2 d$. One was more anxious to climb a hill quickly than to climb it cheaply. The question into which he had entered was merely one of power. In answer to the Chairman he would say that the tank appeared to act almost entirely in the same way as the Thornycroft boiler, in which the tubes entered above the water line. The water would stand half way down in the gauge, and yet circulated freely above that line and poured out of the top of the rising pipes. The body of water coming out of these pipes at the top was, he thought, partly carried up by the small quantity of steam which had been formed. Finally he assured the Meeting that he had never ventured to close the top of the tank, and would be sorry to do so. 